\title{
Therapeutic communication skills in palliative care nursing education: an exploratory study using a role-playing tool
}

\section{Carlos Laranjeira ${ }^{1,2}$, Ana Querido ${ }^{1,2}$, Catarina Afonso ${ }^{2,3}$}

${ }^{1}$ Center for Innovative Care and Health Technology (ciTechcare), Polythecnic of Leiria, Portugal, ${ }^{2}$ School of Health Sciences, Polythecnic of Leiria, Portugal, ${ }^{3}$ ACES Pinhal Litoral, Leiria, Portugal.

\begin{abstract}
This study aim to explore the experiences of nursing final-year students on the care of the person in a palliative situation and their family using the roleplaying technique. Qualitative, descriptive research developed in October 2020 with 30 third-year nursing students from a palliative care nursing course, in Portugal. Individual debriefing reflections and thematic analysis of the information were conducted. Two main themes emerged: 1) facilitators; and 2) barriers of role-playing in a simulated palliative care context. We concluded that type of simulation allows students to deal with complex palliative care situations from an individual and realistic perspective.
\end{abstract}

Keywords: Caring; palliative care nursing; role-playing; nursing students; metacognition. 


\section{Introduction}

In the context of the pandemic COVID-19 that we are going through, one of the actions that have been valued by teachers and educational institutions is the adoption of active teachinglearning methodologies in nursing education. The use of active strategies contributes to overcoming the pitfalls of traditional education model, centred on the positivism approach, focusing on strengthening instrumental ability without teaching with a transforming perspective. The educator has the role of transferring knowledge. The student has a submissive posture in which the content is acquired without reflection and/or critical understanding (Sebold et al., 2018). Active methodologies seek to empower students so that they can manage their training process. For the implementation of changes in the teaching paradigms in health and nursing, the relevance of critical pedagogy and emancipatory education stands out, from which it is possible to foster critical reflection and the collective and dialogical construction of knowledge, based on the integration of theory-practice based on a concrete social reality (Canever et al., 2017).

Among the active pedagogical strategies, role-playing is configured as a relevant teaching method for educational and recreational purposes. A facilitator elaborates a fictitious situation in which students assume other individuals' social role and experience clinical problems that they experience (Sebold et al., 2018). They make it possible to awaken the critical-reflexive look and train skills that make them capable of transforming reality in the professional future (Nemec, Brower \& Allert, 2020). Therefore, it is a student-centred strategy and allows learning in a pedagogical environment, supported by reflection and guided by a facilitator.

Role-playing can be used as a low-fidelity clinical simulation of the standardized or simulated patients [people acting in prescribed roles] type, as long as it follows clinical simulation principles (Negri et al., 2017). In this situation, "the experience and learning occur through other individuals, students, or actors taught/instructed by the facilitator to consistently portray the patient according to the intended reality" (Sebold et al., 2018, p.2707). Studies that used role-playing as a learning strategy emphasize its importance for self-knowledge, the humanization of care, the improvement of communication and other social interaction skills, as well as the articulation from theory to real care situations (Smith et al., 2018; Yu \& Kang, 2017).

Nursing students rarely have experience with the dying population due to faculty viewing these cases as undesirable and as "not good teaching cases" (Sadhu et al., 2010, p.157). Nursing schools have not adequately incorporated Palliative Care (PC) into the curriculum to increase PC content and skills awareness. Sadhu et al. (2010) asserted that students lack knowledge of PC. Students cannot be expected to be experts in any capacity due to lack of experience in the clinical arena; however, schools and hospitals are holding students and new 
graduates accountable for this material and expect an adequate competency level despite lack of training and teaching subject. To better prepare students to care for dying individuals, the implementation of PC experiences within the nursing curriculum is critical (Randall, Garbutt \& Barnard, 2018).

Given the role-playing contributions to nursing education, the interest to use the strategy to problematize with nursing students the meanings and practices related to nursing care for people in palliative situations arose. This option is justified not only by the centrality and importance of care as a central core of professional nursing practice but also by the need to develop attitudes and interpersonal skills to perform care beyond the instrumental component.

\subsection{Objective}

We performed a pilot study to explore nursing final-year students' experiences on the care of the person in a palliative situation and their family using role-play technique.

\section{Methods}

This is a descriptive study with a qualitative approach developed in October 2020. We chose qualitative methodology as a reference for the study since it is the one that best illustrates the process of understanding to be achieved.

\subsection{Recruitment}

The authors recruited third-year students from a palliative care nursing course. Participation was voluntary, and students had no previous experience with this type of simulation. Thirty subjects consent to take part and participated in a scripted role-play scenario.

\subsection{Role-play simulation}

In preparation for the simulation session, students were divided into three groups of 10 senior nursing students. Each group was assigned their room with a table and chairs for each participant and had one faculty facilitator. Facilitators are provided with a timeline, a guide for debriefing, and an evaluation rubric. After a 5-minute introduction and orientation to the activity, learners began reviewing the case scenario (discussing palliative actions with terminal illness patients and their families). The students then briefly reviewed their roles and started their role-play. The facilitator observed and took note of whether the students addressed the scenario-specific competencies. Three students were asked to play the role of 
nurse (1) who had provided palliative care to a patient (2) and were making a joint visit to provide psychoemotional support to his wife (3).

Following the simulated role-play session, facilitators used group feedback and debriefing to reflect and critically appraise the learning outcomes (see Table 1). This strategy allows participants to offer additional ideas and insights from the seemingly neutral point-of-view of an "outside" and to provide feedback on the learning goal that was negotiated at the beginning of the encounter (Jackson \& Back, 2011). Besides, the facilitators led the discussion among all groups to enable the students to generalize the situations and outcomes after gaining experiences, so that they could use the experiences in practice. Students were encouraged to write a reflexive diary to explore and reflect on PC issues addressed in simulated scenario, using Gibbs' reflective cycle. Reflection helps a professional become more self-regulated, conscious, and self-critical (Braun et al., 2013; Mann, Gordon \& MacLeod, 2009). Schön (1991) defined clinical reflection related to action as "reflection-inaction", whereby students reflect on their own experiences during practice and then, after the simulation experience, reflect on the actions they took, critically examining what they did and learned, or what worked and what did not work.

This study is based on the students' analysis of the students' written reflections produced at the curricular unit or PC Nursing. Doing this helps us better understand the phenomenon studied, role-playing, and explain the feelings, concerns, and fears that students experience when carrying out the role-playing.

Table 1. Learning outcomes of the simulation session

1. Promote self-reflection in the context of working with patients/families on PC;

2. Recognize the importance of teamwork in PC;

3. Demonstrate the use of appropriate therapeutic communication;

4. Demonstrate skills on the conduction of sensitive conversations;

\subsection{Data analysis}

To encode and analyze the data, they were categorized according to the information extracted from students' reflections. The data was analyzed using using thematic analysis as a research method and was reviewed independently by two team members to identify recurring themes (Braun \& Clarke, 2006). 


\section{Results and Discussion}

The analysis showed that 22 of the students were female, and eight were male; all were aged 20-35. The information obtained in individual reflections were grouped according to a thematic axis in two thematic units: recognizing the facilitators and barriers of role-playing in a simulated palliative care context.

a) Facilitators in the learning experience

Overall, students evaluated this learning experience positively and felt the simulated roleplay session was useful and enjoyable. During the simulation session, the students actively participated in the whole activity to exchange knowledge and experiences. Some positive points were identified: a) the ability to interpret the indicated clinical case; b) identification of priorities in PC Nursing; c) a confident and humanized attitude towards the patient/family; and d) the application of prior theoretical knowledge during the simulation, articulating theory and practice. In this sense, the simulation provides meaningful learning, co-created from a teaching-learning space, to effectively contribute to implementing a nursing practice centred on the person and their condition.

Students who participate in palliative care simulation experiences that allow them to hone their communication skills report feeling better prepared to care for dying patients in their first year of professional practice (Glover et al., 2017; Glover et al., 2019). One of the participants said: It helped me feel a little bit more self-confident [...]. With the use of roleplaying, it was possible to experience situations arising from nursing's daily practice. This practice-based simulation enabled the construction and development of knowledge and practical skills in a meaningful way, fulfilling the role of active methodology in the teachinglearning process. Another participant wrote: We can put the acquired knowledge into practice to better approach specific situations [...]. It is, therefore, a problem situation that the student can analyze, reflect and articulate his/her knowledge, giving it meaning and adapting it to the experiences already experienced and his/her discoveries. This form of learning is called significant and causes modification/transformation in the individual who experiences it, either in the individual's behaviour, in the future orientation he/she chooses or in his/her attitudes and personality. It is intense learning, which is not limited to progress in a quantitative way in terms of knowledge but intensifies the meaning of the lived experience with a reflection on the action.

b) Barriers in the learning experience

Insecurity, anxiety and doubts about dealing with the terminally ill person were raised as negative points; how to take care of the family, and the difficulty of communication. A student participant says: Insecurity, overwhelming situations and inexperience are a clear obstacle to putting into practice the skills needed in interpersonal relationships. That is why 
role-playing is so very important [...]. However, it was mentioned by the students that simulating, before immersing themselves in clinical practice in a real context, allows for the training of skills necessary to perform nursing care and to deepen theoretical knowledge. Simulation makes the experience closer to the real, being considered an adequate teaching practice when providing immersion and the lived experience. Learning is individual and collective, allowing to reduce anxiety and foster the development of confidence in the actions performed. In the face of inappropriate conduct, it can be reviewed and redone without compromising the patient's safety. We suggest that students might need a solid foundation of understanding their own beliefs and conceptions of death and dying upon which to base their learning about palliative and end-of-life care. Students who have recent experience, or are experiencing, a threat to the life of a close relative or friend or who are caring for someone who is dying may find their core beliefs and conceptions of death and dying being challenged.

Death is seen as a difficult topic of discussion. The feelings and emotions associated with death and dying underscored the importance of psychosocial care of all students involved. Besides, the issues of denial, grief, fear and acceptance were stressed as part of the learning of the psychological processes of death (Glover et al., 2019). One participant stated: We learn a lot from classmates and criticism from the group and teachers. The topic of death is so complex ... I don't know what to say to patients and families. This recurrent theme of death and dying revealed the importance of include this topic in the teaching-learning processes at PC Nursing.

\subsection{Limitations}

We recognize that this study has several limitations. The sample size was small and the work was conducted within a single institution. The differences between male and female students in the way that they approach learning was not analysed. Each nursing student's knowledge would vary depending on the time spent with the palliative patient cared for and clinical experiences offered, which could create a limitation on PC exposure. Another limitation to this study included the personal experiences of each particular nursing student in PC. Personal experiences could consist of having a family member, friend, or acquaintance who accessed PC services. Personal experiences with PC could create either a negative or positive outlook on PC for the student, depending on the individual experience.

\section{Conclusion}

This role-play activity allows students to practice therapeutic communication and shared decision-making, both with patient and family presence and in premeeting rounds with the health care team. PC exposure during student training helps trainees recognize the impact of high-quality interprofessional conversations on the care patients want and ultimately receive. 
This study demonstrates the benefits of role-playing in teaching palliative care communication skills and the value of including multiple disciplines in this educational process. Role-playing appears to be a promising intervention for teaching palliative care communication skills in an interdisciplinary setting. This simulation strategy encouraged students to empathize with the dying patient and provided an opportunity for students to become aware of their own biases, fears and emotions. Therefore, the role-playing reveals to foster metacognition and reflection-in-action in a safe environment. Future research should be continue to explore this practice for teaching multiple skills in an interdisciplinary approach and should be developed with a gender perspective.

\section{References}

Braun, V., Clarke, V. (2006). Using thematic analysis in psychology. Qualitative Research in Psychology, 3, 77-101. doi:10.1191/1478088706qp063oa

Braun, U., Gill, A., Teal, C., \& Morrison, L. (2013). The utility of reflective writing after a palliative care experience: can we assess medical students' professionalism?. Journal of palliative medicine, 16(11), 1342-1349. https://doi.org/10.1089/jpm.2012.0462

Canever, B., Prado, M., Gomes, D., Jesus, B. \& Backes, V. (2017). Naive world awareness in the pedagogical practice of healthcare professors. Texto \& Contexto - Enfermagem, 26(2), e3340015. https://doi.org/10.1590/0104-07072017003340015.

Glover, T., Horgas, A., Castleman, J., Turpening, P. \& Kittelson, S. (2017). An experiential learning approach to primary palliative care nursing education: the comfort shawl project. Journal of Hospice and Palliative Nursing, 19(6), 534-538.

Glover, T., Åkerlund, H., Horgas, A., \& Bluck, S. (2019). Experiential Palliative Care Immersion: Student Nurse's Narratives Reflect Care Competencies. Western Journal of Nursing Research, 41(10), 1465-1480. https://doi.org/10.1177/0193945919833061

Jackson, V. A., \& Back, A. L. (2011). Teaching communication skills using role-play: an experience-based guide for educators. Journal of palliative medicine, 14(6), 775-780. https://doi.org/10.1089/jpm.2010.0493

Mann, K., Gordon, J., \& MacLeod, A. (2009). Reflection and reflective practice in health professions education: a systematic review. Advances in health sciences education: theory and practice, 14(4), 595-621. https://doi.org/10.1007/s10459-007-9090-2

Negri, E., Mazzo, A., Martins, J., Pereira, G., Junior, Almeida, R., \& Pedersoli, C. (2017). Clinical simulation with dramatization: gains perceived by students and health professionals. Revista latino-americana de enfermagem, 25, e2916. https://doi.org/10.1590/1518-8345.1807.2916

Nemec, R., Brower, E., \& Allert, J. (2020). A Guide to Implementing Role-Play in the Nursing Classroom. Nursing education perspectives, Advance online publication. https://doi.org/10.1097/01.NEP.0000000000000678

Randall, D., Garbutt, D., \& Barnard, M. (2018). Using simulation as a learning experience in clinical teams to learn about palliative and end-of-life care: A literature review. Death studies, 42(3), 172-183. https://doi.org/10.1080/07481187.2017.1334006 
Sadhu, S., Salins, N., \& Kamath, A. (2010). Palliative Care Awareness among Indian Undergraduate Health Care Students: A Needs-Assessment Study to Determine Incorporation of Palliative Care Education in Undergraduate Medical, Nursing and Allied Health Education. Indian journal of palliative care, 16(3), 154-159. https://doi.org/10.4103/0973-1075.73645

Schön D. (1991). The Reflective Practitioner. 2nd ed. San Francisco: Jossey Bass.

Sebold, L., Boell, J., Fermo, V., Girondi, J., \& Santos, J. (2018). Role-playing: teaching strategy that encourages reflections on nursing care. Revista Brasileira de Enfermagem, 71(Suppl. 6), 2706-2712. https://dx.doi.org/10.1590/0034-7167-2017-0733

Smith, M., Macieira, T., Bumbach, M., Garbutt, S., Citty, S., Stephen, A., Ansell, M., Glover, T., \& Keenan, G. (2018). The Use of Simulation to Teach Nursing Students and Clinicians Palliative Care and End-of-Life Communication: A Systematic Review. The American journal of hospice \& palliative care, 35(8), 1140-1154. https://doi.org/10.1177/1049909118761386

Yu, M., \& Kang, K. (2017). Effectiveness of a role-play simulation program involving the sbar technique: A quasi-experimental study. Nurse education today, 53, 41-47. https://doi.org/10.1016/j.nedt.2017.04.002 